\title{
Heterogeneous time-dependent response of adipose tissue during the development of cancer cachexia
}

\author{
M L Batista Jr ${ }^{1,3}$, R X Neves ${ }^{1,3}$, S B Peres ${ }^{2,4}$, A S Yamashita ${ }^{3}$, C S Shida ${ }^{5}$, S R Farmer ${ }^{4}$ and M Seelaender ${ }^{3}$ \\ ${ }^{1}$ Laboratory of Adipose Tissue Biology, Center for Integrated Biotechnology, University of Mogi das Cruzes, Avenida Doutor Cândido Xavier de Almeida Souza, \\ 200 Vila Partênio, Mogi das Cruzes, Sao Paulo 08780-911, Brazil \\ ${ }^{2}$ Department of Physiological Sciences, State University of Maringa, Maringa, Parana, Brazil \\ ${ }^{3}$ Cancer Metabolism Research Group, Institute of Biomedical Sciences, University of Sao Paulo, Sao Paulo, Brazil \\ ${ }^{4}$ Department of Biochemistry, Boston University School of Medicine, Boston, Massachusetts, USA \\ ${ }^{5}$ Institute of Science and Technology, Federal University of São Paulo, Sao Paulo, Brazil \\ (Correspondence should be addressed to M L Batista Jr; Email: migueljr4@me.com)
}

\begin{abstract}
Cancer cachexia induces loss of fat mass that accounts for a large part of the dramatic weight loss observed both in humans and in animal models; however, the literature does not provide consistent information regarding the set point of weight loss and how the different visceral adipose tissue depots contribute to this symptom. To evaluate that, 8 -week-old male Wistar rats were subcutaneously inoculated with $1 \mathrm{ml}$ $\left(2 \times 10^{7}\right)$ of tumour cells (Walker 256). Samples of different visceral white adipose tissue (WAT) depots were collected at days $0,4,7$ and 14 and stored at $-80{ }^{\circ} \mathrm{C}$ (seven to ten animals/each day per group). Mesenteric and retroperitoneal depot mass was decreased to the greatest extent on day 14 compared with day 0 . Gene and protein expression of PPAR $\gamma 2$ (PPARG) fell significantly following tumour implantation in all three adipose tissue depots while $\mathrm{C} / \mathrm{EBP} \alpha$
\end{abstract}

(CEBPA) and SREBP-1c (SREBF1) expression decreased over time only in epididymal and retroperitoneal depots. Decreased adipogenic gene expression and morphological disruption of visceral WAT are further supported by the dramatic reduction in mRNA and protein levels of perilipin. Classical markers of inflammation and macrophage infiltration $(\mathrm{f} 4 / 80, \mathrm{CD} 68$ and MIF-1 $\alpha$ ) in WAT were significantly increased in the later stage of cachexia (although showing a incremental pattern along the course of cachexia) and presented a depot-specific regulation. These results indicate that impairment in the lipid-storing function of adipose tissue occurs at different times and that the mesenteric adipose tissue is more resistant to the 'fat-reducing effect' than the other visceral depots during cancer cachexia progression.

Journal of Endocrinology (2012) 215, 363-373

\section{Introduction}

Cachexia is a complex metabolic syndrome that is a common end point shared by many chronic diseases, such as chronic heart failure, chronic obstructive pulmonary disease (COPD) and chronic renal failure (Tisdale 2010, Fearon 2011), but is most commonly observed in cancer patients. During the development of cancer cachexia, a well-characterised loss of both adipose tissue and skeletal muscle occurs (Dahlman et al. 2010, Arner 2011). It has been proposed that the former often precedes and is more rapid than the latter (Fouladiun et al. 2005). Several factors culminate in loss of adipose tissue, such as 1) increased lipid mobilisation due to enhanced adipocyte lipolysis (Agustsson et al. 2007, Ryden et al. 2008, Arner 2011), 2) reduced lipogenesis due to decreased lipoprotein lipase activity (Tisdale 2009) and 3) impairment of fat cell turnover, which results in a disruption in the formation and development of adipose tissue (Arner \& Spalding 2010).
This knowledge should lead to a deeper understanding of the disease and development of appropriate interventions that might be more effective in preventing or delaying the onset of this syndrome.

Adiposity is controlled in part by alterations in the secretion of adipokines that control adipocyte metabolism as well as regulate diverse physiological processes in other tissues including the skeletal muscle, liver and brain (Fearon et al. 2006). In addition, adipose tissue mass is influenced by a finely regulated process of conversion of mesenchymal stem cells into mature adipocytes in response to a variety of extracellular effectors (Vernochet et al. 2009). These effectors coordinate the expression of an elaborate network of transcriptional factors that orchestrate the production of hundreds of proteins responsible for establishing the adipocyte lineage and subsequent differentiation (adipogenesis) into mature fat cells (Farmer 2005). At the centre of this process are the two principal adipogenic factors, PPAR $\gamma(\operatorname{PPARG})$ and 
$\mathrm{C} / \mathrm{EBP} \alpha$ (CEBPA), which captain the entire terminal differentiation process. PPAR $\gamma$ is considered the master regulator of adipogenesis; precursor cells lacking this transcriptional factor are unable to develop into fully functional adipocytes capable of lipid metabolism and secretion of adipokines (Rosen et al. 2009). Interestingly, progenitor cells that do not express $\mathrm{C} / \mathrm{EBP} \alpha$ are still capable of differentiating into adipocytes; however, the resulting $\mathrm{C} / \mathrm{EBP} \alpha$-deficient adipocytes are insulin resistant (Rosen et al. 2009). SREBP-1c (SREBF1) is an additional factor participating in adipocyte maturation by regulating the expression of genes encoding target enzymes involved in the biosynthesis of fatty acids.

Involuntary weight loss, such as that present in cancer cachexia, causes a decrease in the size of adipocytes without changes in their number, resulting in adipose tissue atrophy (Bing \& Trayhurn 2009). Bing et al. (2006) showed that the epididymal adipose tissue (EAT) of cachectic mice contained shrunken adipocytes with dramatically reduced cell size that may have resulted from the down-regulation of key adipogenic and lipogenic factors. However, the authors have not provided any information regarding the onset of the syndrome or whether the dysfunction occurs in other adipose tissue depots.

White adipose tissue (WAT) is a heterogeneous tissue displaying marked depot-related specialisation in relation to many parameters, including cellularity, growth, metabolism, production of and response to cytokines as well as hormones, innervation and fatty acid composition (reviewed by Pond (1999, 2002)). Previous studies from our group using an animal model of cachexia have shown that different depots are heterogeneously and in a time-dependent fashion affected by the syndrome (Bertevello \& Seelaender 2001, Machado et al. 2004). Nevertheless, whether there is a corresponding timedependent and site-specific change in the way fat loss occurs is still controversial.

To gain greater insight into adipose tissue wasting during the development of cancer cachexia and into the associated morphological and molecular mechanisms, we have analysed different WAT depots at three time points following tumour injection. We herein present results regarding 1) the time course of adipose tissue atrophy during cachexia progression, 2) circulating adipokine profile, 3) changes in the levels of mRNA and in protein expression of key adipogenic factors and of factors controlling specific functions of the mature adipocyte and 4) the presence of inflammatory cells and the association between infiltration and the alterations of the other parameters. The analysis shows profound early alterations in the expression of major adipogenic and lipogenic transcriptional factors followed by morphological modifications of the adipocytes, which become more evident at the late stage of the disease. In addition, the results suggest that the mesenteric adipose tissue (MEAT) is more resistant to the 'fat-reducing effect' elicited by the tumour than the other visceral depots studied during the cancer cachexia progression.

\section{Materials and Methods}

\section{Animals}

Male adult Wistar rats (160-250 g), obtained from the Institute of Biomedical Sciences, University of São Paulo, were maintained in metabolic cages, in a $12 \mathrm{~h}$ light: $12 \mathrm{~h}$ darkness cycle (lights on at $0700 \mathrm{~h}$ ), under controlled temperature conditions $\left(23 \pm 1{ }^{\circ} \mathrm{C}\right)$, receiving water and food (NuvilabCR1-Nuvital ${ }^{\circledR}$, Curitiba, Paraná, Brasil) ad libitum. The Ethical Committee for Animal Research from the Institute of Biomedical Sciences, University of São Paulo approved all the adopted procedures, which were carried out in accordance with the ethical principles stated by the Brazilian College of Animal Experimentation.

Weight and food intake were assessed daily, always in the afternoon. Walker 256 tumour cells $\left(2 \times 10^{7}\right.$ cells) were injected s.c. into the right flank of the animals (Seelaender et al. 1998). Control rats received saline injections on the same day of tumour inoculation. Cachectic syndrome is observed in rats bearing Walker 256 tumour cells after 10-15 days (Bennani-Baiti \& Walsh 2011). To evaluate the development of cancer cachexia, the experiments were carried out in the time course study, when the rats were killed on days $4,7,10$ or 14 post-injection (seven to ten animals on each time point) by decapitation after $12 \mathrm{~h}$ fasting.

\section{Blood samples and adipose tissue collection}

Trunk blood was collected after decapitation into $15 \mathrm{ml}$ conical bottom Falcon tubes containing EDTA $\left(1.8 \mathrm{mg} / \mathrm{ml}\right.$ of blood), centrifuged at $500 \mathrm{~g}$ and $4{ }^{\circ} \mathrm{C}$ for $10 \mathrm{~min}$, and stored at $-80^{\circ} \mathrm{C}$. EAT, retroperitoneal adipose tissue (RPAT) and MEAT (after careful removal of adjacent lymph nodes) were removed, weighed, snap frozen in liquid nitrogen and stored at $-80^{\circ} \mathrm{C}$.

\section{Plasma and tissue analysis}

General plasma markers and adipokine concentration The concentration of triacylglycerol, glucose and total protein was measured by commercial kits. Adiponectin was measured by ELISA (EZRADP-62K, Millipore, Inc., Billerica, MA, USA) and leptin by RIA with the species-specific kit RL-83K (Linco Research, Inc., Saint Charles, Missouri, USA). The sensitivity of adiponectin assay was $0.15 \mathrm{ng} / \mathrm{ml}$, and the inter-assay coefficient of variation $(\mathrm{CV})$ ranged from $4 \cdot 3$ to $8 \cdot 4 \%$. The sensitivity of leptin assay was $1 \mathrm{ng} / \mathrm{ml}$, and the inter-assay $\mathrm{CV}$ ranged from $3 \cdot 0$ to $5 \cdot 7 \%$.

Light microscopy After fragmentation and fixation (4\% paraformaldehyde, $\mathrm{pH} 7 \cdot 2$ ) for $16 \mathrm{~h}$ at $4{ }^{\circ} \mathrm{C}$, adipose tissue samples were dehydrated in absolute ethanol, cleared in xylene and then embedded in paraffin. The paraffin was cut into $5 \mathrm{~mm}$ sections that were stained with Harris 
haematoxylin, counterstained with eosin and then analysed under light microscopy (Leica, DM 750). For the analysis of the morphometrical aspects, the area, approximate diameter, perimeter and shape factor were measured in 100 adipocytes (five slides per tissue from one rat, five animals per group). A total of 1500 cells per group were studied. Analysis of the results was performed using the Sigma ScanPro4 program.

Real-time PCR Total RNA was isolated from the EAT, RPAT and MEAT samples using TRIzol (Invitrogen) following the manufacturer's recommendations. The concentrations of RNA were determined by measuring the absorbance at $260 \mathrm{~nm}$. The purity of the RNA was determined by calculating the absorbance ratio at 260 and $280 \mathrm{~nm}$, and by ethidium bromide staining. RT-PCR was performed on the total RNA (4 $\mu \mathrm{g})$, which was used for firststrand synthesis of cDNA using a commercially available kit (Ambion, Austin, TX, USA). The reaction mixture was stored at $-80{ }^{\circ} \mathrm{C}$ until the PCR step. Primer sets for rat perilipin (NM 013094.1: sense, 5'-GCC TAT GAG AAG GGT GTA CAG G-3' and antisense, 5'-CTT CAG TTC AGA GGC GAT CTT T-3'), PPAR $\gamma 2$ (NM 001145366.1: sense, 5'-CTG CCT ATG AGC ACT TCA CAA-3' and antisense, $5^{\prime}$-CAT CAC AGA GAG GTC CAC AGA G-3'), C/EBP $\alpha$ (NM 012524.2: sense, 5'-GAA GTC GGT GGA TAA GAA CAG C- $3^{\prime}$ and antisense, $5^{\prime}$-GGT CAT TGT CAC TGG TCA ACT C-3'), SREBP-1c (XM 213329.5: sense, $5^{\prime}$-AGG GAG TTC TCA GAT GCT CTT G-3' and antisense, 5'-CAT GCT GGA ACT GAC AGA GAA G-3'),

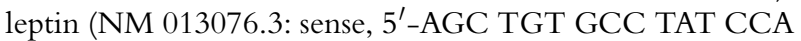
CAA AGT CCA- ${ }^{\prime}$ and antisense, $5^{\prime}$-AAT GAA GTC CAA ACC GGT GAC CCT-3'), adiponectin (NM 144744.3: sense, $5^{\prime}$-ATC CTG CCC AGT CAT GAA GGG ATT-3' and antisense, $5^{\prime}$-TGC CAT CCA ACC TGC ACA AGT TTC-3'), resistin (NM 144741.1: sense, 5'-ACTA GCT GCT CCT GTG GCT CT- $3^{\prime}$ and antisense, $5^{\prime}$-CAG TCT ATG CTT CCG CAC TG-3'), haptoglobin (NM 012582.2: sense, 5'-CCT GCC TTC CAA AGA CTA CG-3' and antisense, $5^{\prime}$-CTC ACA CTT CTC CTG GTC AGC- $3^{\prime}$ ), CD68 (NM 001031638.1: sense, 5'-ACA AAC AGT CCA

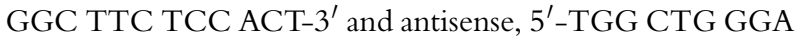
ACC ATT AGT CCA TGT-3'), F4/80 (NM 001007557.1: sense, $5^{\prime}$-CTC TTC CTG ATG GTG AGA AAC C- $3^{\prime}$ and antisense, 5'-CCC ATG GAT GTA CAG TAG CAG A-3') and macrophage migration inhibitory factor (MIF; NM 031051.1: sense, 5'-TCC CGG ACC ACG TCA TGA CTT T- $3^{\prime}$ and antisense, $5^{\prime}$-CGT TGG CTG CGT TCA TGT CGT AAT-3') were designed using Primer Express Software v2.0 (Applied Biosystems). The results for mRNA concentrations are expressed as a ratio over $18 \mathrm{~S}$ rRNA, which was amplified as a housekeeping gene using the following primers: 18S rRNA (M11188.1: sense, $5^{\prime}$-TCA GCT TTG CAA CCA TAC TCC- $3^{\prime}$ and antisense, $5^{\prime}$-GAC CAT AAA CGA TGC CGA CT-3'). For each sample, PCR was performed in duplicate in a $25 \mu \mathrm{l}$ reaction volume of 5-20 ng of cDNA, $12.5 \mu \mathrm{l}$ Syber Green Master Mix
(Applied Biosystems), and 200-600 nM of each primer. PCR analyses were carried out using the following cycle parameters: $50{ }^{\circ} \mathrm{C}$ for $2 \mathrm{~min}, 95^{\circ} \mathrm{C}$ for $10 \mathrm{~min}$, followed by 40 cycles of $95^{\circ} \mathrm{C}$ for $15 \mathrm{~s}$ and $60^{\circ} \mathrm{C}$ for $1 \mathrm{~min}$. Fluorescence was quantified and analyses of amplification plots were performed with the ABI Prism 7700 Sequence Detector System (Applied Biosystems). All samples were normalised to the $18 \mathrm{~S}$ values and the results were expressed as fold changes of $C t$ value relative to controls using the $2^{-\Delta \Delta C t}$ formula. $18 \mathrm{~S}$ was used as a reference gene as we have experimentally determined that there were no statistically significant differences of its $C$ t values between control and different times from tumour-bearing groups (both $P<0 \cdot 05$, three experiments).

Western blotting Frozen tissue $(0 \cdot 1-0 \cdot 3 \mathrm{~g})$ was homogenised $(1: 5)$ in RIPA buffer $(0.625 \%$ Nonidet P-40, $0.625 \%$ sodium deoxycholate, $6.25 \mathrm{mM}$ sodium phosphate and $1 \mathrm{mM}$ ethylenediaminetetraacetic acid at $\mathrm{pH} 7 \cdot 4$ ) containing $10 \mu \mathrm{g} / \mathrm{ml}$ of a protease inhibitor cocktail (Sigma-Aldrich). Homogenates were centrifuged at $12000 \mathrm{~g}$ for $10 \mathrm{~min}$ at $4{ }^{\circ} \mathrm{C}$, the supernatants (fatty layer) were discarded and the infranatant was saved. Protein concentration was determined with a BCA protein quantification kit (Pierce, Rockford, IL, USA), with BSA as a reference. Samples containing $50 \mu \mathrm{g}$ protein were separated by electrophoresis on a $10 \%$ SDS-PAGE. Proteins were then transferred to PVDF membranes at $100 \mathrm{~V}$ for $1 \mathrm{~h}$ in a transfer buffer containing $20 \mathrm{mM}$ Tris, $150 \mathrm{mM}$ glycine and $10 \%$ methanol. PVDF membranes were then blocked in TBS containing $0 \cdot 1 \%$ Tween 20 and 5\% milk for $1 \mathrm{~h}$. After three washes with TBS- $0 \cdot 1 \%$ Tween, the PVDF membranes were incubated with primary antibodies against $\mathrm{C} / \mathrm{EBP} \alpha$ (polyclonal Abcam 74404) at a 1:5000 dilution, PPAR $\gamma$ (polyclonal Abcam 19481) and perilipin (polyclonal Abcam 3526) at a 1:2000 dilution, and adiponectin (polyclonal Abcam 62551) at a 1:2000 dilution and hormone-sensitive lipase (HSL; polyclonal Abcam 45422), all over night. After three washes with TBS- $0 \cdot 1 \%$ Tween, the PVDF membranes were incubated with secondary antibodies goat anti-rabbit IgG conjugated to HRP (Santa Cruz Biotechnology, Inc.) at 1:5000 for $1 \mathrm{~h}$ at room temperature and were detected by ECL (Amersham, Little Chalfont, UK). For the control of protein equal loading, blots were stripped and then incubated with $\beta$-tubulin (polyclonal thermo RB-9249-P0). Quantification of antigen-antibody complexes was performed using Image J Analysis Software (http://rsb.info.nih.gov/ij/). Optical density units are expressed in pixel for fold target protein/control protein.

Statistical analysis Data are expressed as mean values \pm s.E.M. Differences between time of tumour cell inoculation (cachexia development, days $0,4,7$ and 14) were analysed by one-way ANOVA followed by Bonferroni's post-hoc comparisons tests using GRAPHPAD PRISM software for Macintosh, version 5.0 (GraphPad, San Diego, CA, USA). Differences between qualitative variables on days 7 and 14 
against control (matched by age) were determined by the unpaired form of the Student's $t$-test, using the same software, and $P<0.05$ was considered significant for all statistical tests.

\section{Results}

Adipose tissue is not only considered the most important energetic reservoir of the body but is also recognised as an active endocrine tissue. Its functionality is affected by a set of physiological and non-physiological events such as cachexia, which is a syndrome frequently observed in cancer patients. The paraneoplastic disease causes lipodystrophy as part of the overall wasting of affected individuals. To investigate the effects of cachexia on adipose tissue with regard to disease course and anatomical-specific aspects, Walker 256 tumour cells were injected s.c. Tumour-bearing rats presented considerably reduced body weight compared with nontumour-bearing controls $(8 \cdot 4 \%, P<0 \cdot 05)$ on day 14 , with no changes on day 7 (Table 1). Tumour burden on day 7 postinoculation represents $8 \%$ and on day $14,29 \%$ of total body mass. Fat mass weight (absolute and relative to body weight) was also markedly reduced in both MEAT and RPAT of tumour-bearing rats on day 14 when compared with nontumour-bearing controls (absolute: 39\% (MEAT) and 32\% (RPAT), and relative: 31 (MEAT) and 26\% (RPAT), both depots $P<0 \cdot 001$; Table 1$)$. There was no change in absolute and relative weight of EAT. Decreased chow consumption was evident from day 10 after inoculation in the tumourbearing rats (data not shown).

Animals bearing the tumour showed statistical differences in absolute and relative weights of the different fat pads during the development of cancer cachexia, suggesting the possibility that modification of cell morphology contributes to these changes. In order to address this hypothesis, we determined cell perimeter and cross-sectional area among the three depots studied (Fig. 1). Light microscopy examination showed that morphometric alterations of adipose tissue in tumour-bearing rats during the progression of cancer cachexia are depot specific (Fig. 1Aa, b, c, d, e, f, g, h and i). In MEAT, adipocyte size, determined as cell perimeter (Fig. 1B) and sectional area (Fig. 1C), showed an increase of $52 \%(P<0 \cdot 05)$ and $1 \cdot 3$-fold $(P<0 \cdot 001)$ respectively on day 14 . Conversely, the cell perimeter of RPAT and EAT adipocytes was reduced (54 and $27 \%$ respectively, $P<0.05$ ) as well as the sectional area (85 and $47 \%$ respectively, $P<0 \cdot 05)$ on day 14 compared with day 0 . On the other hand, MEAT showed an unexpectedly opposite effect concerning morphology, i.e. increased perimeter and section area. These data illustrate a regional and heterogeneous fat distribution in tumour-bearing rats.

Considering that the diameter of cells measured in MEAT was slightly affected by the presence of the tumour and continued to enlarge during cachexia progression, we put forward the question whether protein and mRNA expression of perilipin, one of the major lipid-coating proteins, would also be increased (Fig. 2A). In this aspect, we also evaluated protein expression of HSL (LIPE), a key enzyme in the regulation of WAT lipolysis (Fig. 3). In MEAT, the reduction in perilipin mRNA levels was only evident on day 14 $(76 \%, P<0 \cdot 01)$. By contrast, perilipin mRNA levels in RPAT and EAT dramatically decreased by $92(P<0 \cdot 001)$ and $55 \%(P<0.01)$ on day $4 ; 97$ and $77 \%$ on day 7 ; and 98 and $57 \%$ on day 14 respectively $(P<0.001$ for both days and tissues) compared with control (day 0). Perilipin protein levels were reduced only on day 14 in MEAT $(91 \%, P<0 \cdot 01)$ and RPAT $(77 \%, P<0 \cdot 01)$ compared with control (day 0, Fig. 2B). There was no change in perilipin protein expression in EAT. HSL protein expression was just affected by cachexia on day 14 , showing increase of $64 \%$ in relation to day 0 . There was no alteration on protein expression on RPAT and EAT considering the different time period evaluated.

To gain additional insight into the reasons why the tumour induced a regional response on fat cell diameter and number, we examined the expression of the major transcription factors

Table 1 General characteristics of animal groups during the progression of cancer cachexia. Values are mean \pm S.E.M. for seven animals per group

\begin{tabular}{|c|c|c|c|c|}
\hline \multicolumn{5}{|c|}{ Tumour cell inoculation (days) } \\
\hline & \multicolumn{2}{|c|}{ Day 7} & \multicolumn{2}{|c|}{ Day 14} \\
\hline & Control & TB & Control & TB \\
\hline$n$ & 7 & 12 & 7 & 14 \\
\hline Body weight (g) & $269 \cdot 1 \pm 19 \cdot 4$ & $265 \cdot 9 \pm 17 \cdot 4$ & $312 \cdot 7 \pm 11 \cdot 6$ & $286 \cdot 4 \pm 12 \cdot 2^{*}$ \\
\hline Tumour weight (g) & & $3 \cdot 0 \pm 1 \cdot 4$ & & $10 \cdot 1 \pm 6 \cdot 4$ \\
\hline MEAT $(g)$ & $1 \cdot 3 \pm 0 \cdot 3$ & $1 \cdot 3 \pm 0 \cdot 3$ & $2 \cdot 5 \pm 0 \cdot 5$ & $1 \cdot 5 \pm 0 \cdot 2 *$ \\
\hline MEAT (\% BW) & $0 \cdot 5 \pm 0 \cdot 1$ & $0 \cdot 5 \pm 0 \cdot 1$ & $0 \cdot 8 \pm 0 \cdot 2$ & $0 \cdot 5 \pm 0 \cdot 1 *$ \\
\hline RPAT (mg) & $1 \cdot 5 \pm 0 \cdot 4$ & $1 \cdot 4 \pm 0 \cdot 4$ & $3 \cdot 5 \pm 0 \cdot 5$ & $2 \cdot 1 \pm 0 \cdot 5^{*}$ \\
\hline RPAT (\% BW) & $0 \cdot 5 \pm 0 \cdot 1$ & $0 \cdot 5 \pm 0 \cdot 2$ & $1 \cdot 1 \pm 0 \cdot 2$ & $0 \cdot 7 \pm 0 \cdot 2 *$ \\
\hline EAT $(m g)$ & $2 \cdot 1 \pm 0 \cdot 4$ & $2 \cdot 0 \pm 0 \cdot 4$ & $3 \cdot 5 \pm 0 \cdot 4$ & $3 \cdot 0 \pm 0 \cdot 3$ \\
\hline EAT (\% BW) & $0 \cdot 8 \pm 0 \cdot 1$ & $0 \cdot 8 \pm 0 \cdot 2$ & $1 \cdot 1 \pm 0 \cdot 1$ & $1 \cdot 1 \pm 0 \cdot 1$ \\
\hline
\end{tabular}

TB, tumour-bearing; MEAT, mesenteric adipose tissue; RPAT, retroperitoneal adipose tissue; EAT, epididymal adipose tissue; BW, body weight. $* P<0 \cdot 05$ vs control. 
A
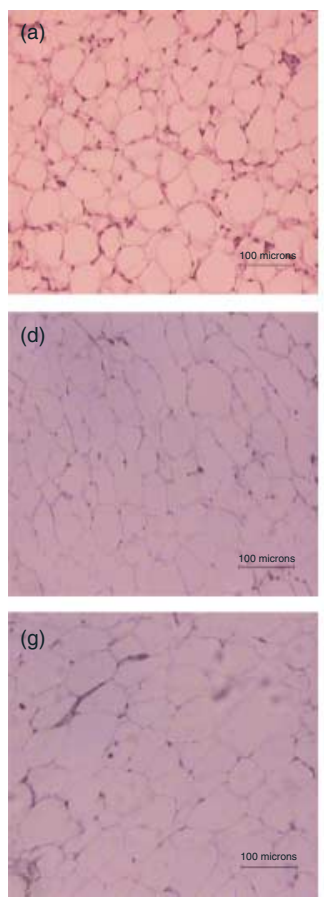
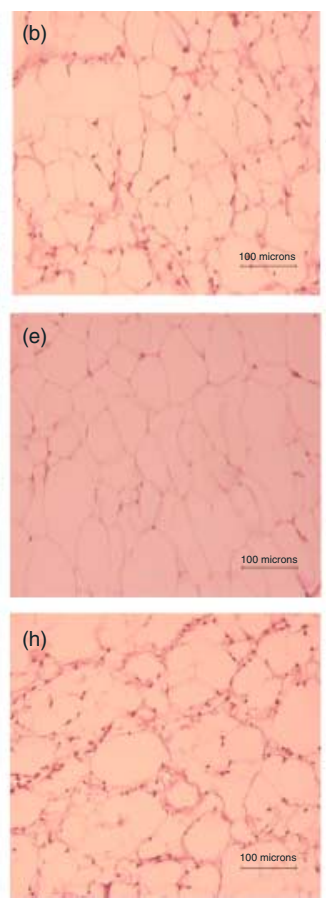
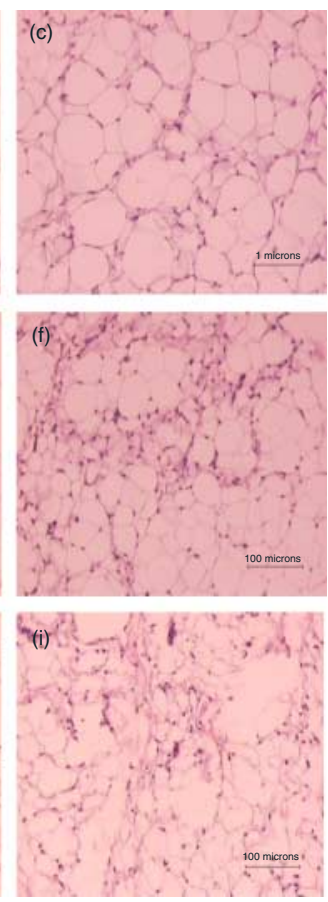

B
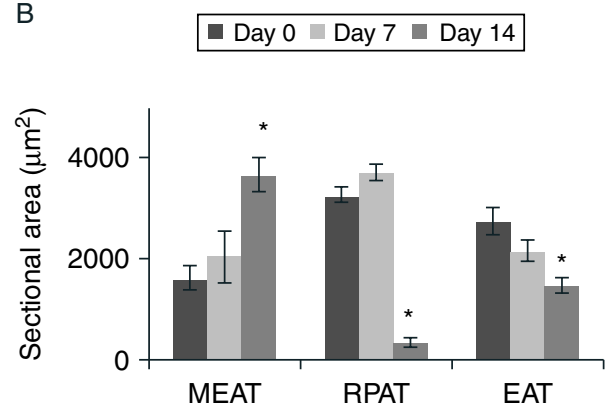

C

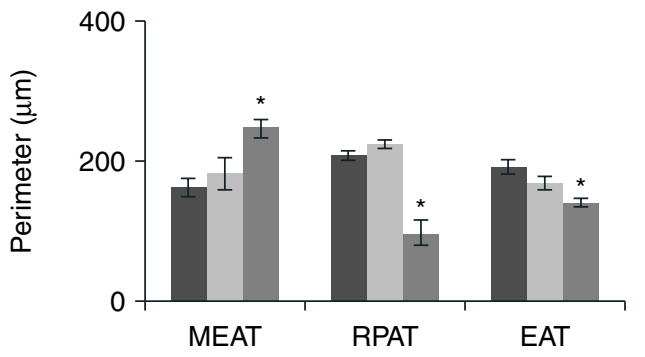

Figure 1 Morphological characteristics of different adipose tissue depots during cancer cachexia progression. (A) Haematoxylin and eosin-stained sections of MEAT tissue from tumour-bearing rats at control (a), day 7 (d) and day 14 (g); RAPT at control (b), day 7 (e) and day $14(\mathrm{~h})$ and EAT at control (c), day 7 (f) and day 14 (i). Morphometrical analysis of sectional area (B) and (C) perimeter of adipocytes from different depots in different time period ( 0,7 and 14 days after tumour cells inoculation). MEAT, mesenteric adipose tissue; RPAT, retroperitoneal adipose tissue; EAT, epididymal adipose tissue. Values are mean \pm s.E.M. for seven animals per group. ${ }^{*} P<0 \cdot 05$ vs Control (day 0). Full colour version of this figure available via http://dx.doi.org/10.1530/EJE-12-0307.

involved in fat cell formation, $\operatorname{PPAR} \gamma 2, \mathrm{C} / \mathrm{EBP} \alpha$ and SREBP-1c (Fig. 2A). Protein and mRNA expression of PPAR $\gamma 2$ fell throughout the 14 days of the experimental protocol in the three depots. Regarding PPAR $\gamma 2$ mRNA levels in MEAT and RPAT, there were decreases of $75 \%(P<0 \cdot 001)$ and $57 \%(P<0 \cdot 01)$ respectively on day 4 ; in MEAT, RPAT and EAT, they dropped 38, 51 and $73 \%(P<0.05)$ respectively on day 7 and $86,72.6$ and $82 \%(P<0 \cdot 01)$ respectively on day 14 compared with day 0 (Fig. 2A). PPAR $\gamma 2$ protein level was reduced in all evaluated depots at day 14 (MEAT, 56.7\%; RPAT, 76\% and EAT, $75 \%, P<0 \cdot 01$; Fig. 2B). PPAR $\gamma 2$ protein level was reduced in all evaluated depots at day 7 (MEAT, 69\%; RPAT, 83\% and EAT, 74\%, $P<0 \cdot 01$ ) and day 14 (MEAT, 57\%; RPAT, 76\% and EAT, 75\%, $P<0 \cdot 01$ ) (Fig. 2B).

$\mathrm{C} / \mathrm{EBP} \alpha \mathrm{mRNA}$ expression, another key regulator of fat cell formation, also declined over time but only in EAT and RPAT depots while in MEAT the expression remained stable. RPAT and EAT showed reductions of $84 \%(P<0 \cdot 001)$ and $62 \%(P<0.001)$ on day 4 and 90 and $78 \%$ on day 7 respectively $(P<0.001$ for both) (Fig. 2A). We also determined protein expression of the $\mathrm{C} / \mathrm{EBP} \alpha$ isoforms of 42 and $30 \mathrm{kDa}$ in total extracts of the three depots (Fig. 2B). $\mathrm{p} 42 \mathrm{C} / \mathrm{EBP} \alpha$ expression levels decreased in RPAT at day 7 $(51 \%, P<0 \cdot 05)$ and day $14(48 \%, P<0 \cdot 05)$, while expression of $\mathrm{p} 30 \mathrm{C} / \mathrm{EBP} \alpha$ was not detected at any of the times. In EAT, though, the pattern of expression was opposite: p30 $\mathrm{C} / \mathrm{EBP} \alpha$ was present on day 0 and down-regulated on day $7(66 \%, P<0 \cdot 05)$ and day $14(62 \%, P<0 \cdot 05)$, but $\mathrm{p} 42$ $\mathrm{C} / \mathrm{EBP} \alpha$ was detectable only on day 7. Moreover, the expression of $\mathrm{p} 42 \mathrm{C} / \mathrm{EBP} \alpha$ in MEAT increased progressively during the course of cachexia (day $7,36 \%, P<0.05$ and day $14,1 \cdot 5$-fold, $P<0 \cdot 01$ ), with no significantly consistent changes in $\mathrm{p} 30 \mathrm{C} / \mathrm{EBP} \alpha$, suggesting that $\mathrm{p} 42 \mathrm{C} / \mathrm{EBP} \alpha$ is probably mediating the stability of fat cells in this depot. Finally, the mRNA expression of SREBP-1c, a transcription factor involved in aspects of adipocyte maturation, increased twofold $(P<0 \cdot 001)$ in MEAT on day 14 compared with day 0 , with no significant changes during the earlier time periods. In RPAT and EAT, there was a reduction of $86.9 \%(P<0 \cdot 001)$ and $80 \%(P<0 \cdot 001)$ on day $4 ; 46$ and $73 \%$ on day 7 and 85 and $33 \%$ on day 14 respectively $(P<0 \cdot 001$ for both days and tissue $)$ in relation to day 0 .

Our next aim was to investigate whether the changes in PPAR $\gamma$ and $\mathrm{C} / \mathrm{EBP} \alpha$ expression correlated with the alterations in the synthesis and secretion of adipokines by adipocytes into the circulation. Adipokines as well as metabolic parameters were evaluated during cancer cachexia progression (Table 2). Plasma glucose and total protein levels were reduced by $18 \%(P<0 \cdot 01)$ and 
A
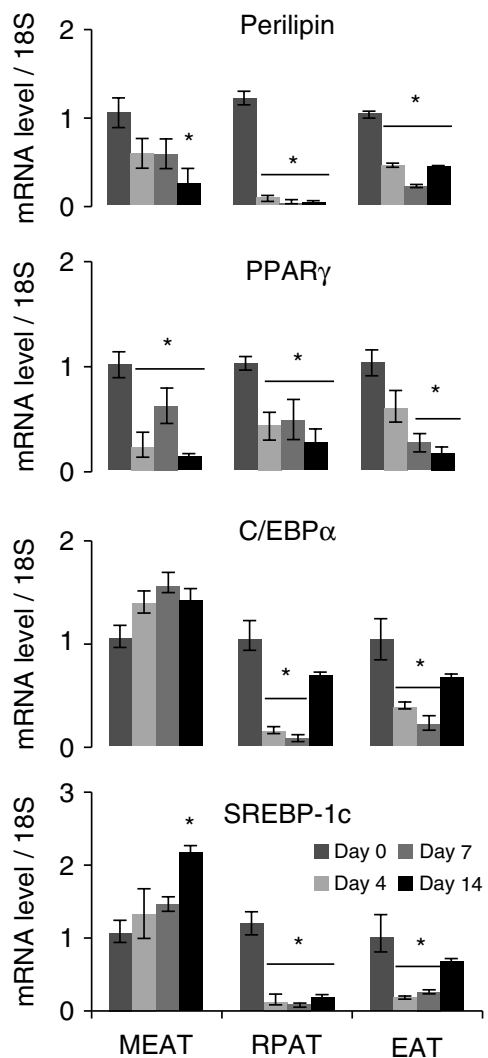

B

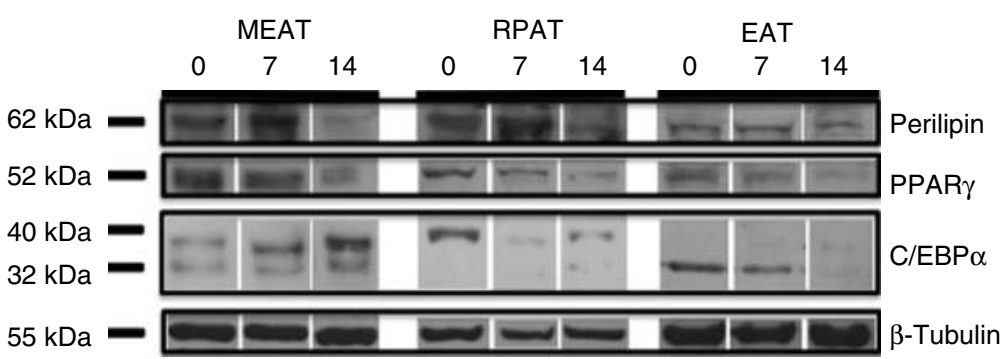

Perilipin
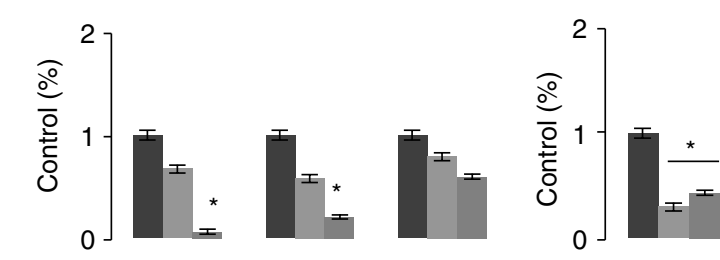

PPAR $\gamma$
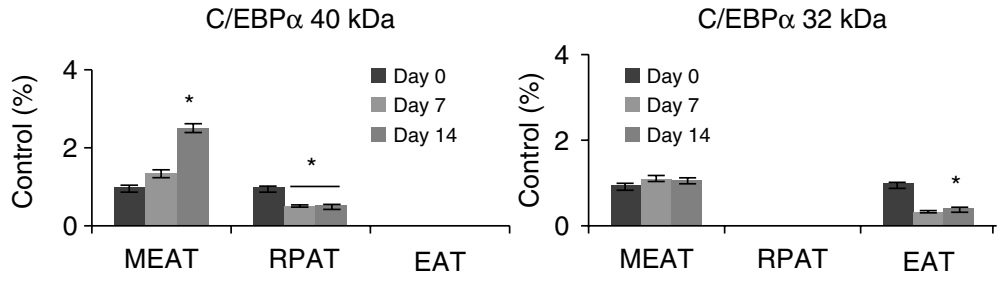

Figure 2 Expression levels of genes involved in relation to lipid-coating proteins and adipogenesis (A) in different adipose tissue depots during cancer cachexia development. Real-time PCR analysis of RNA isolated from MEAT, RPAT and EAT of control (day 0), 7 and 14 days after tumour cell inoculation. mRNA levels of target genes were normalised to 18S. Values are mean \pm s.E.M. for seven animals per group. $* P<0 \cdot 05$ vs control (day 0). (B) Western blotting analysis of protein extracts from different adipose tissue depots. Blots were rearranged and most representative images were selected for perilipin, PPAR $\gamma, \mathrm{C} / E B P \alpha$ and for SREBP-1c and $\beta$-tubulin proteins (normalised protein). MEAT, mesenteric adipose tissue; RPAT, retroperitoneal adipose tissue; EAT, epididymal adipose tissue. Values are mean \pm s.E.M. for five animals per group. ${ }^{*} P<0 \cdot 05$ vs control (day 0$)$.

$19 \%(P<0 \cdot 01)$ respectively on day 14 compared with day 0. Total plasma triglyceride increased, $22 \%(P<0 \cdot 05)$ on day 7 and $30 \%(P<0 \cdot 01)$ on day 14 , when compared with the control (day 0). Plasmatic values for adiponectin, an adipokine with effects on insulin sensitivity, were elevated by $54 \%$ $(P<0 \cdot 01)$ on day 4 , yet returned to basal values on day 7 , finally decreasing by $26 \%(P<0 \cdot 05)$ on day 14 . Resistin plasma levels rose about $1 \cdot 8$-fold $(P<0 \cdot 01)$ on day 7 , returning to basal values on day 14 . Finally, we determined leptin plasma levels, an adipokine displaying a plethora of regulating effects on the control of energy intake and expenditure, among many others. Our results show a reduction of leptin levels on day 14 . In addition, we evaluated the expression of adipokine genes including adiponectin, leptin, resistin and haptoglobin, as shown in Fig. 4. Adiponectin mRNA levels in MEAT showed an increase of four-, five- and two-fold $(P<0 \cdot 001)$ on days 4,7 and 14 respectively. RPAT and EAT levels were reduced by $57 \%$ $(P<0 \cdot 01)$ and $60 \%(P<0 \cdot 01)$ on day $4 ; 51$ and $84 \%$ on day 7 and 72 and $84 \%$ on day 14 respectively $(P<0 \cdot 001$ for both days and tissues) compared with day 0 . Regarding adiponectin, we also determined its protein expression (Fig. 3). Adiponectin expression levels increased in MEAT at day $7(1 \cdot 1$-fold, $P<0 \cdot 05)$ and day $14(70 \%, P<0 \cdot 05)$. In RPAT, there was a decrease at day $14(54 \%, P<0 \cdot 05)$, while expression in EAT samples were not detected at any of the times. Resistin did not differ in any of the tissues in the study period, when compared with day 0 (not shown). Leptin did not change in MEAT in any time point. In RPAT, leptin expression showed a reduction of 67 and $55 \%(P<0 \cdot 05)$ on days 7 and 14 respectively compared with day 0 . In EAT, leptin mRNA levels were lower on day $4(60 \%, P<0 \cdot 01)$, day $7(80 \%, P<0 \cdot 001)$ and day $14(83 \%, P<0 \cdot 001)$ when compared with control. Haptoglobin showed an increase by three- and four-fold $(P<0 \cdot 001)$ on day 7 in MEAT and RPAT respectively and in the three analysed depots (MEAT, RPAT and EAT) on day 14 , by $11-, 2-$ and 3 -fold $(P<0 \cdot 001)$ respectively when compared with day 0 (Fig. 4). 

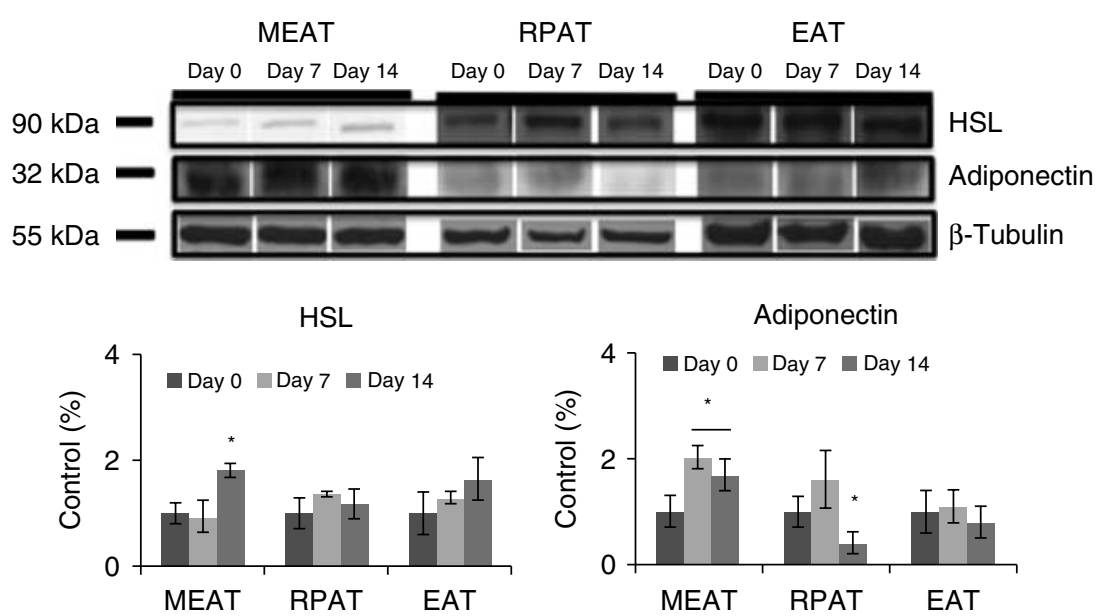

Figure 3 Western blotting analysis of protein extracts from MEAT, RPAT and EAT of control (day 0 ), 7 and 14 days after tumour cells inoculation. Blots were rearranged and most representative images were selected for adiponectin and HSL and $\beta$-tubulin proteins (normalised protein). MEAT, mesenteric adipose tissue; RPAT, retroperitoneal adipose tissue; EAT, epididymal adipose tissue; HSL, hormone-sensitive lipase. Values are mean \pm s.E.M. for five animals per group. ${ }^{*} P<0 \cdot 05$ vs control (day 0 ).

In order to evaluate the presence of infiltrated cells in cachexia-affected adipose tissue, the gene expression of CD68, f4/80 and MIF was determined in the different pads during the progression of the disease (Fig. 4). In MEAT and RPAT, an increase in CD68 mRNA levels was evident on day 4 (3- and 2.5-fold), day 7 (8- and 3.7-fold) and day 14 $(8 \cdot 8-$ and $7 \cdot 8$-fold $)$ respectively $(P<0 \cdot 001)$. In EAT, changes were detected solely on day 14 , with an increase of $1 \cdot 4$-fold $(P<0 \cdot 05)$. $44 / 80$ mRNA expression increased on day 14 in all adipose tissue depots (MEAT, threefold; RPAT, fourfold; and EAT, fivefold, $P<0 \cdot 01)$. In addition, in MEAT, the change started already on day 7 , with an increase of $10 \%(P<0 \cdot 01)$, when compared with day 0 . MIF mRNA expression showed an increase only on day 14 (3.7-fold in MEAT, $P<0 \cdot 01$, $3 \cdot 6$-fold and $77 \%$ (RPAT and EAT respectively, $P<0 \cdot 05$ ) when compared with day 0 .

\section{Discussion}

In this study, we demonstrated several morphological and molecular changes in three different adipose tissue depots of rats during the progression course of cancer cachexia. Most of the alterations were initiated before any detectable morphological disruption, notably through down-regulation of genes related to adipogenesis, metabolism and mature adipocyte function. Changes in plasma adiponectin levels occurred in a parallel manner to the down-regulation of WAT genes, indicating possible disturbances in signalling systems that control WAT homoeostasis. In addition, adipose tissue inflammation, a well-characterised symptom of cachexia, was most apparent at the late stage.

Cancer cachexia induces wasting of fat mass that accounts for a large part of the dramatic weight loss observed both in humans (Fouladiun et al. 2005, Agustsson et al. 2007, Dahlman et al. 2010) and in animals (Machado et al. 2004, Bing et al. 2006, Asp et al. 2010), and lipid metabolism is markedly altered (Seelaender $e$ t al. 1996, Tisdale 2009, Arner 2011). Walker 256-induced cachexia was efficient at eliciting loss of body weight in terms of both absolute and relative weight (percentage of total body mass) of the fat depots, with consequent abnormalities in plasma biochemical profile. While MEAT and RPAT mass decreased to the greatest extent, at least on day 14 (with no change in the intermediary

Table 2 Biochemical and adipokine levels of animal groups during the development of cancer cachexia. Values are mean \pm S.E.M. for seven animals per group

\begin{tabular}{|c|c|c|c|c|c|}
\hline Parameters & Day 0 & Day 4 & Day 7 & Day 10 & Day 14 \\
\hline TAG (mg/dl) & $65 \pm 18$ & $66 \pm 19$ & $84 \pm 25$ & $85 \pm 18$ & $93 \pm 17^{*}$ \\
\hline Glucose $(\mathrm{mg} / \mathrm{ml})$ & $135 \pm 6$ & $125 \pm 8$ & $125 \pm 11$ & $120 \pm 8^{*}$ & $113 \pm 13^{*}$ \\
\hline Protein $(\mu \mathrm{g} / \mu \mathrm{l})$ & $44 \pm 5 \cdot 0$ & $44 \pm 5 \cdot 0$ & $44 \pm 7$ & $40 \pm 6$ & $37 \pm 5^{*}$ \\
\hline Adiponectin (ng/ml) & $9 \cdot 6 \pm 0 \cdot 7$ & $14 \cdot 8 \pm 1 \cdot 1^{*}$ & $9 \cdot 6 \pm 1 \cdot 5$ & $8 \cdot 0 \pm 1 \cdot 0$ & $7 \cdot 3 \pm 0 \cdot 5^{*}$ \\
\hline Leptin $(\mathrm{ng} / \mathrm{ml})$ & $1 \cdot 4 \pm 0 \cdot 2$ & $1 \cdot 2 \pm 0 \cdot 2$ & $1 \cdot 2 \pm 0 \cdot 3$ & $1 \cdot 0 \pm 0 \cdot 3$ & $0 \cdot 7 \pm 0 \cdot 3 *$ \\
\hline Resistin (ng/ml) & $5 \cdot 9 \pm 1 \cdot 7$ & $6 \cdot 2 \pm 1 \cdot 0$ & $17 \cdot 0 \pm 7 \cdot 6^{*}$ & $8 \cdot 1 \pm 2 \cdot 0$ & $3 \cdot 9 \pm 1 \cdot 4$ \\
\hline
\end{tabular}

TAG, triacylglycerol. $* P<0 \cdot 05$ vs control. 

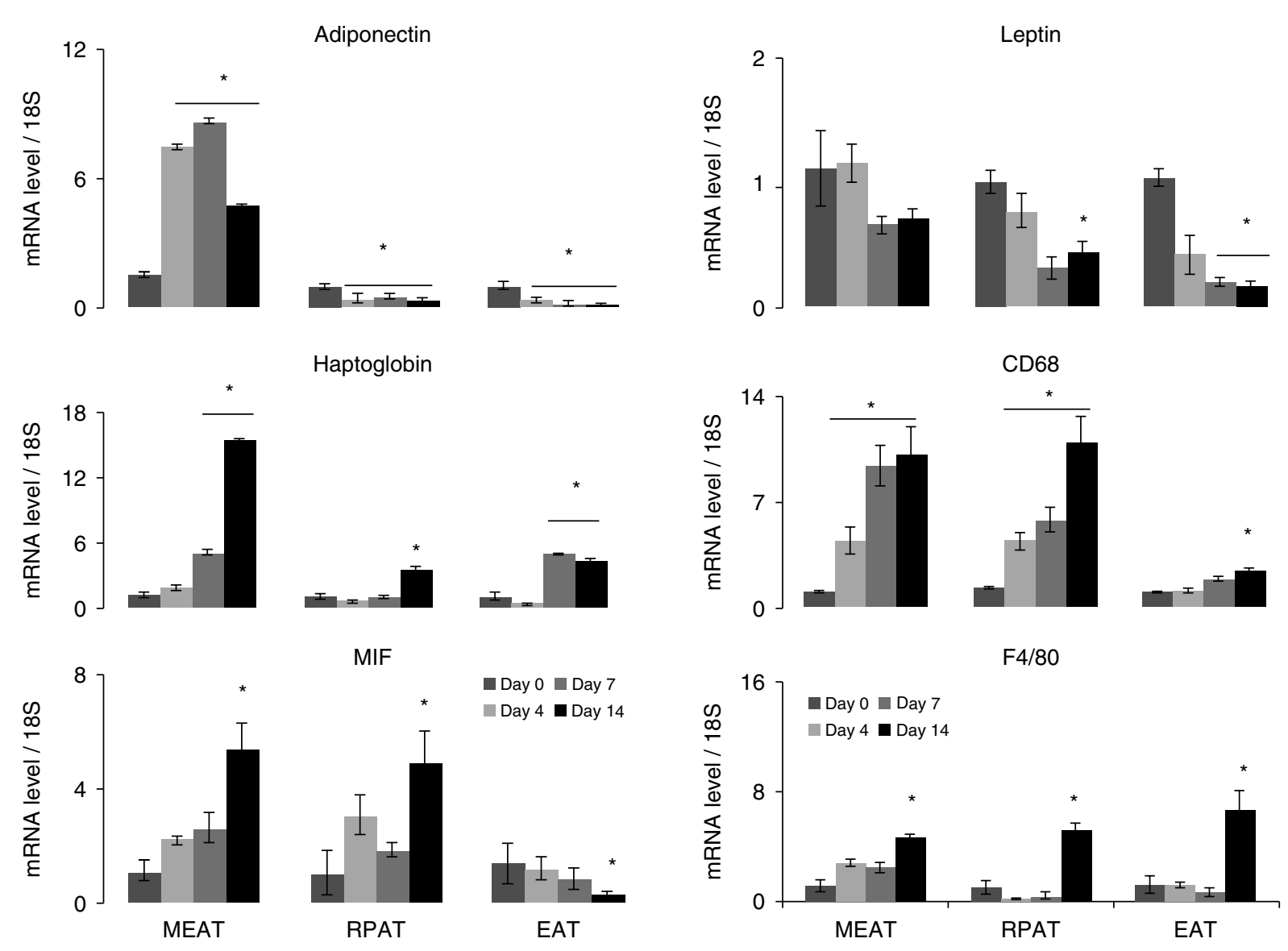

Figure 4 Expression levels of genes involved in mature adipocyte function and in inflammation in different adipose tissue depots during cancer cachexia progression. Real-time PCR analysis of RNA isolated from MEAT, RPAT and EAT of control (day 0 ), 7 and 14 days after tumour cell inoculation. mRNA levels of target genes were normalised to 18S. MEAT, mesenteric adipose tissue; RPAT, retroperitoneal adipose tissue; EAT, epididymal adipose tissue; MIF, macrophage migration inhibitory factor. Values are mean \pm S.E.M. for seven animals per group. ${ }^{*} P<0 \cdot 05$ vs control (day 0 ).

stage of cachexia - day 7), the mass of EAT did not differ from control. This finding is in agreement with our previous study (Machado et al. 2004) and we further demonstrate that reduction in WAT depot weight (absolute and relative) of Walker 256 tumour-bearing rats seems to occur only on the 14th day post-inoculation (after which animals spontaneously die due to cachexia). Adipocyte morphometrical data also changed in the late stage of cachexia, at which time cells from MEAT were found to be larger compared with day 0 . By contrast, there was a decrease in the size of the RPAT and EAT cells at the same time point. It is important to note that, at in this point (day 7), there was no difference in absolute and relative WAT weight of all depots. During normal physiological animal growth, there is an increase in the mass of WAT depots, which occurs in parallel to increases in body weight, an aspect well characterised by DiGirolamo et al. (1998), who measured adipocyte cell volume. The development of cachexia (days 7-14) affected this pattern, nevertheless in a way that is dependent on the anatomical localisation of the fat pad: while there was increase in the size of MEAT adipocytes, cachexia caused significant decreases in the size of RPAT and EAT cells (both related to normal tissue growth). Rat MEAT has been shown (DiGirolamo et al. 1998) to grow mainly by hypertrophy and normally contains a higher percentage of water than RPAT and EAT. RPAT expansion under physiological conditions occurs predominantly by hyperplasia (DiGirolamo et al. 1998), but the results obtained here suggest that cachexia is able to induce a dual effect: hypertrophy on day 7 , probably due to normal tissue growth, followed by atrophy on the day 14, probably cachexia induced. EAT showed a reduction in the size of adipocytes in the course of cachexia (day 14), with no changes in relative tissue weight. These regional-specific responses are probably related to the degree of innervation, vascularisation and depot-specific concentration of hormones and cytokines (Pond 1999).

In cancer cachexia, a substantial diminishment in gene transcription of PPAR $\gamma, \mathrm{C} / \mathrm{EBP} \alpha$ and SREBP-1c was already demonstrated in WAT from mice (epididymal 
depot; Bing et al. 2006). We extend this finding by evaluating the expression of adipogenic genes in other visceral depots. PPAR $\gamma$ mRNA levels showed a conspicuous decrease in all depots evaluated (MEAT, RPAT and EAT) beginning on day 4 following the injection of tumour cells (early-stage cachexia). Ablation of PPAR $\gamma 1$ and PPAR $\gamma 2$ from the mature adipocytes results in a moderate reduction of adipose mass, which is accompanied by hyperlipidaemia, liver steatosis and protection from high-fat diet-induced increase in adiposity (Jones et al. 2005, Heikkinen et al. 2007). Given that PPAR $\gamma$ is an essential transcriptional regulator of adipogenesis and is required for maintenance of mature adipocyte function, including triglyceride synthesis and storage (Yahagi et al. 1999), we also evaluated its protein expression. A reduction in protein expression was evident on day 14 in all visceral depots evaluated, indicating that, despite heterogeneity of adipose tissue, PPAR $\gamma$ is equally disrupted in the late stage of cachexia. In fact, our data demonstrate that in the three depots, there was an extensive reduction in gene as well as in the protein expression of PPAR $\gamma$, but the levels of $\mathrm{C} / \mathrm{EBP} \alpha$ and SREBP-1c only decreased in the retroperitoneal and epididymal depots. On the other hand, the mesenteric depot showed a striking increase in the expression of SREBP-1c and $\mathrm{C} / \mathrm{EBP} \alpha$, gene and protein respectively. This is particularly interesting and sheds some light on the explanation of why the mesenteric adipocytes were not significantly affected by the 'fat-reducing effect' imposed by the tumour, as observed in the other depots. Previous studies have clearly demonstrated the importance of C/EBP $\alpha$ in regulating fat cell formation and function. Furthermore, $\mathrm{C} / \mathrm{EBP} \alpha$ also triggers the expression of SREBP- $1 \mathrm{c}$, which in turn modulates the lipogenic capacity of adipocytes. Several lipogenic enzymes have their expression induced by SREBP-1c including ATP citrate lyase, acetyl-CoA carboxylase and fatty acid synthase. We have not measured the expression of any SREBP-1c target genes in our study, but it is reasonable to expect a reduction in their expression in EAT and RPAT throughout the 14-day protocol and an opposite pattern of expression in MEAT, which could explain a lower lipogenic ability of EAT and RPAT.

The visceral and subcutaneous white fat is recognised as the largest sites of adipokine production in the body. Adipokine expression is highly increased during adipocyte differentiation and tightly controlled by PPAR $\gamma$ and $\mathrm{C} / \mathrm{EBP} \alpha$ activity. In this study, the circulating concentration of adiponectin rose almost twofold 4 days after tumour injection, which seems to be particularly influenced by the mesenteric adipose cell contributions, as denoted by the marked enhancement in adiponectin gene expression in this depot, while the other pads presented a negligible change in mRNA and protein expression. Adiponectin expression is modulated by $\mathrm{C} / \mathrm{EBP} \alpha$, as consistently reported by others (Park et al. 2004). The use of siRNA against C/EBP $\alpha$ in 3T3-L1 cells clearly induces a reduction of adiponectin expression (Vernochet et al. 2010). Interestingly, patients with heart failure, who develop cachexia, also present higher levels of adiponectin (McEntegart et al. 2007), and in cancer cachexia patients, this parameter is robustly correlated with body weight loss ( Batista Jret al. 2012). On the other hand, leptin secretion, which has been shown to be positively correlated with fat cell size, decreased by 50\% 14 days after tumour cell inoculation. These data are consistent with a previous publication from our group, in which Walker 256 carcinosarcoma induced a down-regulation of leptin production (Bertevello \& Seelaender 2001, Machado et al. 2004). In addition to that, it has been shown that when isolated human adipocytes are incubated with tumour necrosis factor $(\mathrm{TNF}-\alpha)$, leptin release is inhibited. TNF- $\alpha$ inhibits leptin production in subcutaneous and omental adipocytes from morbidly obese humans (Fawcett et al. 2000).

The presence of adipogenic and morphological defects in visceral WAT in cachexia is further supported by the dramatic reduction in mRNA levels of perilipin. To confirm this alteration, we showed that perilipin protein expression was also reduced on day 14; however, this was just evident in MEAT and RPAT. It is interesting to note that it is the first report, at least as far as we know, showing a down-regulation of perilipin mRNA and protein in fat cells during the development of cancer cachexia in tumour-bearing rats and that, despite the heterogeneity herein related, this reduction is similar in visceral WAT depots. We also evaluated HSL protein expression in different experimental time points and WAT depots. Recently, it has been shown that lipolysis plays an instrumental role in the development of cancer cachexia (Das et al. 2011). Cachexia induced by Walker tumour elicited an increase in HSL protein expression at day 14 only in MEAT depots, indicating that HSL seems to be disrupted in the late stage of cachexia in a depot specific manner. Perilipin is the most abundant protein on the surfaces of adipocyte lipid droplets, being involved in the regulation of basal and hormonally stimulated lipolysis (Brasaemle 2007). In times of energy deficit, perilipin facilitates maximal lipolysis by providing a dynamic scaffold to coordinate access of HSL and adipose triglyceride lipase to the lipid droplet in a manner that is responsive to the metabolic status of the adipocyte (Meijer et al. 2011). However, the exact role of perilipin and HSL in adipose tissue dysfunction in the setting of cachexia requires further investigation.

Haptoglobin is an acute-phase reactant protein secreted into the plasma participating in many biological processes including immune regulation, inflammation and malignancy. The present results demonstrate a massive increment in haptoglobin gene expression in the mesenteric depot, yet less prominent in the other depots. We hypothesise that the reason for such an increase might be related with the participation of $\operatorname{PPAR} \gamma$ and TNF- $\alpha$ as upstream mediators of haptoglobin production. Cancer cachexia induces a scenario with elevated levels of pro-inflammatory cytokines (Argiles et al. 2009, Lira et al. 2012, Seelaender et al. 2012), including TNF- $\alpha$, which in turn could inhibit PPAR $\gamma$ expression and activity but stimulate haptoglobin expression. In this regard, increased levels of gene and protein expression of TNF- $\alpha$ in MEAT of 
Walker 256 tumour-bearing rats is well characterised (Machado et al. 2004, Lira et al. 2012). Confirmation of a lower PPAR $\gamma$ activity in our animals is granted by the observation of reduction in leptin and perilipin expression, as well as a decrease in perilipin protein content.

Appearance of infiltrated cells (leucocytes) and/or mediators of inflammation has been postulated to contribute to the pathogenesis in the development of impaired adipose tissue function and ectopic fat deposition (Bluher 2009); however, it is not clear how these events take place during the development of WAT dysfunction. Therefore, we evaluated gene expression of specific macrophage phenotype ( $\mathrm{f} 4 / 80$ and CD68) and survival (MIF) markers. CD68, a classical macrophage marker, showed up-regulation in all visceral depots on day 14; however, this change began on day 4 in MEAT and RPAT, suggesting an increase in mononuclear cells in adipose tissue during the initial periods of the development of cancer cachexia. These data corroborate our previous study (Machado et al. 2004). However, it is important to note that CD68 is not only restricted to the macrophage lineage but also expressed in fibroblasts, and changes in the adipose tissue matrix environment (fibrosis) may reflect increases in this cell type. To further elucidate the presence of infiltrated macrophages during the development of cancer cachexia, we also evaluated f4/80 gene expression, which was similarly increased in all visceral depots on day 14. Another evaluated gene, MIF, which has an important function as a pleiotropic protein, participating in inflammatory and immune responses as well as in delayed hypersensitivity and various macrophage functions, including phagocytosis, spreading and tumoricidal activity, showed an increase only on day 14 in MEAT and RPAT and, on the other hand, was decreased in EAT. On the other hand, the possible relationship between infiltrated cells and impairment of adipose tissue function needs additional investigations.

In summary, our study demonstrates pronounced molecular and depot-specific alterations of WAT in tumour-bearing animals, which indicate a time-dependent effect of cachexia on adipose tissue. Regarding molecular disruption, downregulation of the key adipogenic factors, as well as repression of lipogenic factors, suggests impairment in the formation and lipid-storing capacity of adipose tissue, which occurs very early during the development of cancer cachexia. Finally, classical markers of inflammation and macrophage infiltration in WAT were only evident in the late-stage cachexia, at the same time that morphological and plasma biochemical disturbance were observed, indicating that several molecular disruptions on WAT occur before establishment of any detectable inflammatory parameter.

\section{Declaration of interest}

The authors declare that there is no conflict of interest that could be perceived as prejudicing the impartiality of the research reported.

\section{Funding}

The research described in this report was supported by FAPESP grant 2007/52782-1and 2010/51078-1.

\section{Acknowledgements}

The authors thank Emilia Ribeiro and Felipe de Oliveira Franco for technical assistance. The contents of this work are solely the responsibility of the authors and do not necessarily represent the official views of the FAPESP.

\section{References}

Agustsson T, Ryden M, Hoffstedt J, van Harmelen V, Dicker A, Laurencikiene J, Isaksson B, Permert J \& Arner P 2007 Mechanism of increased lipolysis in cancer cachexia. Cancer Research 67 5531-5537. (doi:10.1158/0008-5472. CAN-06-4585)

Argiles JM, Busquets S, Toledo M \& Lopez-Soriano FJ 2009 The role of cytokines in cancer cachexia. Current Opinion in Supportive and Palliative Care 3 263-268. (doi:10.1097/SPC.0b013e3283311d09)

Arner P 2011 Medicine. Lipases in cachexia. Science 333 163-164. (doi:10.1126/science.1209418)

Arner P \& Spalding KL 2010 Fat cell turnover in humans. Biochemical and Biophysical Research Communications 396 101-104. (doi:10.1016/j.bbrc. 2010.02.165)

Asp ML, Tian M, Wendel AA \& Belury MA 2010 Evidence for the contribution of insulin resistance to the development of cachexia in tumorbearing mice. International Journal of Cancer 126 756-763. (doi:10.1002/ ijc.24784)

Batista ML Jr, Mireia Olivan M, Alcantara PS, Sandoval R, Peres SB, Neves RX, Silverio R, Maximiano LF, Otoch JP \& Seelaender M 2012 Adipose tissue-derived factors as potential biomarkers in cachectic cancer patients. Cytokine In press.

Bennani-Baiti N \& Walsh D 2011 Animal models of the cancer anorexiacachexia syndrome. Supportive Care in Cancer 19 1451-1463. (doi:10.1007/ s00520-010-0972-0)

Bertevello PS \& Seelaender MC 2001 Heterogeneous response of adipose tissue to cancer cachexia. Brazilian Journal of Medical and Biological Research 34 1161-1167. (doi:10.1590/S0100-879X2001000900009)

Bing C \& Trayhurn P 2009 New insights into adipose tissue atrophy in cancer cachexia. Proceedings of the Nutrition Society 68 385-392. (doi:10.1017/ S0029665109990267)

Bing C, Russell S, Becket E, Pope M, Tisdale MJ, Trayhurn P \& Jenkins JR 2006 Adipose atrophy in cancer cachexia: morphologic and molecular analysis of adipose tissue in tumour-bearing mice. British Journal of Cancer 95 1028-1037. (doi:10.1038/sj.bjc.6603360)

Bluher M 2009 Adipose tissue dysfunction in obesity. Experimental and Clinical Endocrinology \& Diabetes 117 241-250. (doi:10.1055/s-0029-1192044)

Brasaemle DL 2007 Thematic review series: adipocyte biology. The perilipin family of structural lipid droplet proteins: stabilization of lipid droplets and control of lipolysis. Journal of Lipid Research 48 2547-2559. (doi:10.1194/ jlr.R700014-JLR200)

Dahlman I, Mejhert N, Linder K, Agustsson T, Mutch DM, Kulyte A, Isaksson B, Permert J, Petrovic N, Nedergaard J et al. 2010 Adipose tissue pathways involved in weight loss of cancer cachexia. British Journal of Cancer 102 1541-1548. (doi:10.1038/sj.bjc.6605665)

Das SK, Eder S, Schauer S, Diwoky C, Temmel H, Guertl B, Gorkiewicz G, Tamilarasan KP, Kumari P, Trauner M et al. 2011 Adipose triglyceride lipase contributes to cancer-associated cachexia. Science 333 233-238. (doi:10.1126/science.1198973)

DiGirolamo M, Fine JB, Tagra K \& Rossmanith R 1998 Qualitative regional differences in adipose tissue growth and cellularity in male Wistar rats fed ad libitum. American Journal of Physiology 274 R1460-R1467. 
Farmer SR 2005 Regulation of PPAR $\gamma$ activity during adipogenesis. International Journal of Obesity 29 (Suppl 1) S13-S16. (doi:10.1038/ sj.ijo.0802907)

Fawcett RL, Waechter AS, Williams LB, Zhang P, Louie R, Jones R, Inman M, Huse J \& Considine RV 2000 Tumor necrosis factor- $\alpha$ inhibits leptin production in subcutaneous and omental adipocytes from morbidly obese humans. Journal of Clinical Endocrinology and Metabolism 85 530-535. (doi:10.1210/jc.85.2.530)

Fearon KC 2011 Cancer cachexia and fat-muscle physiology. New England Journal of Medicine 365 565-567. (doi:10.1056/NEJMcibr1106880)

Fearon KC, Voss AC, Hustead DS \& Cancer Cachexia Study G 2006 Definition of cancer cachexia: effect of weight loss, reduced food intake, and systemic inflammation on functional status and prognosis. American Journal of Clinical Nutrition 83 1345-1350.

Fouladiun M, Korner U, Bosaeus I, Daneryd P, Hyltander A \& Lundholm KG 2005 Body composition and time course changes in regional distribution of fat and lean tissue in unselected cancer patients on palliative care correlations with food intake, metabolism, exercise capacity, and hormones. Cancer 103 2189-2198. (doi:10.1002/cncr.21013)

Heikkinen S, Auwerx J \& Argmann CA 2007 PPAR $\gamma$ in human and mouse physiology. Biochimica et Biophysica Acta 1771 999-1013. (doi:10.1016/ j.bbalip.2007.03.006)

Jones JR, Barrick C, Kim KA, Lindner J, Blondeau B, Fujimoto Y, Shiota M, Kesterson RA, Kahn BB \& Magnuson MA 2005 Deletion of PPAR $\gamma$ in adipose tissues of mice protects against high fat diet-induced obesity and insulin resistance. PNAS 102 6207-6212. (doi:10.1073/pnas.0306743102)

Lira FS, Yamashita AS, Rosa JC, Koyama CH, Caperuto EC, Batista ML Jr \& Seelaender MC 2012 Exercise training decreases adipose tissue inflammation in cachectic rats. Hormone and Metabolic Research 44 91-98. (doi:10.1055/s-0031-1299694)

Machado AP, Costa Rosa LF \& Seelaender MC 2004 Adipose tissue in Walker 256 tumour-induced cachexia: possible association between decreased leptin concentration and mononuclear cell infiltration. Cell and Tissue Research 318 503-514. (doi:10.1007/s00441-004-0987-2)

McEntegart MB, Awede B, Petrie MC, Sattar N, Dunn FG, MacFarlane NG \& McMurray JJ 2007 Increase in serum adiponectin concentration in patients with heart failure and cachexia: relationship with leptin, other cytokines, and B-type natriuretic peptide. European Heart Journal $\mathbf{2 8}$ 829-835. (doi:10.1093/eurheartj/ehm033)

Meijer K, de Vries M, Al-Lahham S, Bruinenberg M, Weening D, Dijkstra M, Kloosterhuis N, van der Leij RJ, van der Want H, Kroesen BJ et al. 2011 Human primary adipocytes exhibit immune cell function: adipocytes prime inflammation independent of macrophages. PLoS ONE 6 e17154. (doi:10.1371/journal.pone.0017154)

Park BH, Qiang L \& Farmer SR 2004 Phosphorylation of C/EBP $\beta$ at a consensus extracellular signal-regulated kinase/glycogen synthase kinase 3 site is required for the induction of adiponectin gene expression during the differentiation of mouse fibroblasts into adipocytes. Molecular and Cellular Biology 24 8671-8680. (doi:10.1128/MCB.24.19.8671-8680.2004)

Pond CM 1999 Physiological specialisation of adipose tissue. Progress in Lipid Research 38 225-248. (doi:10.1016/S0163-7827(99)00003-X)
Pond CM 2002 Adipose tissue, the immune system and exercise fatigue: how activated lymphocytes compete for lipids. Biochemical Society Transactions $\mathbf{3 0}$ 270-275. (doi:10.1042/BST0300270)

Rosen E, Eguchi J \& Xu Z 2009 Transcriptional targets in adipocyte biology. Expert Opinion on Therapeutic Targets 13 975-986. (doi:10.1517/ 14728220903039706)

Ryden M, Agustsson T, Laurencikiene J, Britton T, Sjolin E, Isaksson B, Permert J \& Arner P 2008 Lipolysis - not inflammation, cell death, or lipogenesis - is involved in adipose tissue loss in cancer cachexia. Cancer 113 1695-1704. (doi:10.1002/cncr.23802)

Seelaender MC, Nascimento CM, Curi R \& Williams JF 1996 Studies on the lipid metabolism of Walker 256 tumour-bearing rats during the development of cancer cachexia. Biochemistry and Molecular Biology International 39 1037-1047.

Seelaender MC, Curi R, Colquhoun A, Williams JF \& Zammitt VA 1998 Carnitine palmitoyltransferase II activity is decreased in liver mitochondria of cachectic rats bearing the Walker 256 carcinosarcoma: effect of indomethacin treatment. Biochemistry and Molecular Biology International 44 185-193.

Seelaender M, Batista MJ, Lira F, Silverio R \& Rossi-Fanelli F 2012 Inflammation in cancer cachexia: to resolve or not to resolve (is that the question?) Clinical Nutrition 31 562-566. (doi:10.1016/j.clnu. 2012.01.011)

Tisdale MJ 2009 Mechanisms of cancer cachexia. Physiological Reviews 89 381-410. (doi:10.1152/physrev.00016.2008)

Tisdale MJ 2010 Cancer cachexia. Current Opinion in Gastroenterology 26 146-151. (doi:10.1097/MOG.0b013e3283347e77)

Vernochet C, Peres SB, Davis KE, McDonald ME, Qiang L, Wang H, Scherer PE \& Farmer SR 2009 C/EBP $\alpha$ and the corepressors CtBP1 and $\mathrm{CtBP} 2$ regulate repression of select visceral white adipose genes during induction of the brown phenotype in white adipocytes by peroxisome proliferator-activated receptor $\gamma$ agonists. Molecular and Cellular Biology 29 4714-4728. (doi:10.1128/MCB.01899-08)

Vernochet C, Davis KE, Scherer PE \& Farmer SR 2010 Mechanisms regulating repression of haptoglobin production by peroxisome proliferator-activated receptor- $\gamma$ ligands in adipocytes. Endocrinolog $\gamma \mathbf{1 5 1}$ 586-594. (doi:10.1210/en.2009-1057)

Yahagi N, Shimano H, Hasty AH, Amemiya-Kudo M, Okazaki H, Tamura Y, Iizuka Y, Shionoiri F, Ohashi K, Osuga J et al. 1999 A crucial role of sterol regulatory element-binding protein- 1 in the regulation of lipogenic gene expression by polyunsaturated fatty acids. Journal of Biological Chemistry 274 35840-35844. (doi:10.1074/jbc.274.50.35840)

\section{Received in final form 4 September 2012 \\ Accepted 2 October 2012 Made available online as an Accepted Preprint 2 October 2012}

